\title{
First Electrochemical Method of Nitrothal-Isopropyl Determination in Water Samples
}

\author{
Dariusz Guziejewski, ${ }^{1}$ Agnieszka Nosal-Wiercińska, ${ }^{2}$ \\ Sławomira Skrzypek, ${ }^{1}$ Witold Ciesielski, ${ }^{1}$ and Sylwia Smarzewska ${ }^{1}$ \\ ${ }^{1}$ Department of Inorganic and Analytical Chemistry, University of Lodz, Lodz, Poland \\ ${ }^{2}$ Department of Analytical Chemistry and Instrumental Analysis, Maria Curie-Skłodowska University, Lublin, Poland \\ Correspondence should be addressed to Dariusz Guziejewski; dguziejewski@uni.lodz.pl
}

Received 4 September 2016; Revised 10 October 2016; Accepted 18 October 2016

Academic Editor: Jorge F. Fernandez-Sanchez

Copyright (C) 2016 Dariusz Guziejewski et al. This is an open access article distributed under the Creative Commons Attribution License, which permits unrestricted use, distribution, and reproduction in any medium, provided the original work is properly cited.

\begin{abstract}
The aim of the research was the use of square wave adsorptive stripping voltammetry (SWAdSV) in conjunction with a hanging mercury drop electrode (HMDE) for the determination of nitrothal-isopropyl. It was found that optimal SW technique parameters were frequency, $200 \mathrm{~Hz}$; amplitude, $50 \mathrm{mV}$; and step potential, $5 \mathrm{mV}$. Accumulation time and potential were studied to select the optimal conditions in adsorptive stripping voltammetry: $45 \mathrm{~s}$ at $0.0 \mathrm{~V}$, respectively. The calibration curve (SWSV) was linear in the nitrothal-isopropyl concentration range from $2.0 \times 10^{-7}$ to $2.0 \times 10^{-6} \mathrm{~mol} \mathrm{~L}^{-1}$ with detection limit of $3.46 \times 10^{-8} \mathrm{~mol} \mathrm{~L}^{-1}$. The repeatability of the method was determined at a nitrothal-isopropyl concentration level equal to $6.0 \times 10^{-7} \mathrm{~mol} \mathrm{~L}^{-1}$ and expressed as RSD $=5.5 \%(n=6)$. The proposed method was successfully validated by studying the recovery of nitrothal-isopropyl in spiked environmental samples.
\end{abstract}

\section{Introduction}

The agricultural practices intensively use pesticides, herbicides, fungicides, and other classes of chemical products to achieve maximal productivity. This has resulted in serious impacts on the natural environment, causing an increased level of pollutant residues in water, soil, river sediments, and foodstuffs $[1,2]$. The elaboration of modern, easy-to-operate, rapid, sensitive, and inexpensive methods for the detection of hazard residues in the environment is a main task in analytical chemistry nowadays. Many published articles report the pollutants determination in natural samples, mainly using separation and spectrometric methods [3].

Fungicides are biocides that are usually applied to protect fruits and vegetables against fungi. The increased risk of fungicide residues accumulation can cause serious health problems also through human exposure to their remnants present in the food. Among the fungicides used, nitrothalisopropyl (diisopropyl 5-nitroisophthalate, NT, Figure 1) is a selective fungicide applied towards control of the development of many side effects of diseases caused by microorganisms in plant breeding of agricultural crops. It has been applied for the control of Podosphaera leucotricha in apple trees, Phytophthora infestans in tomato and potato, and Septoria apii in celery as well as Bremia lactucae in lettuce cultivation. Nitrothal-isopropyl is also applied as a seed treatment, in order to combat diseases of vegetable and ornamental plants. It is used in forestry for diseases causing needles drooping as well. In humans NT can cause eyes, skin, and respiration system irritation. Nitrothal-isopropyl is classified as a third-class toxicity pesticide for mammals.

The most common methods of NT determination employ gas, liquid or thin-layer chromatography and selective detector [4-8]. Voltammetric techniques are described with several advantages like wide linear concentration range, good sensitivity, low apparatus cost, capability of miniaturization, capability for on-site detection, relatively short time of analysis, and insensitivity to matrix effects $[9,10]$. Hanging mercury drop electrode commonly used for characterization of electrode processes and analytical purposes can be characterized with wide range of potential in a negative region, easily renewable and smooth surface, capability 


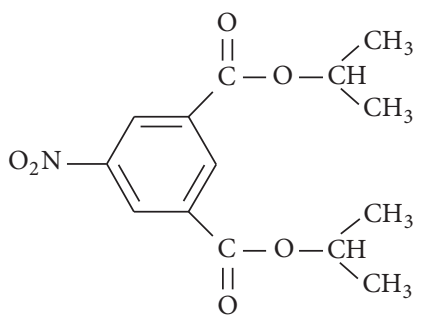

FIGURE 1: Chemical structure of nitrothal-isopropyl.

for preconcentration of analytes, and so forth. Moreover square wave voltammetry (SWV) is recognized as the most frequently used voltammetric technique for electroanalysis [11]. Pulsed voltammetric techniques are acknowledged with relatively low detection profiles ascribed to low background current. The electroanalytical techniques have long history in applications towards analysis of biocides in different environmental matrices [12-15]. Electroanalytical techniques are also advantageous due to characterization possibilities in kinetic and equilibrium studies [16-19]. Investigation of nitro-group containing compounds using voltammetric methods has been utilized since the very beginning of polarography [20] and voltammetry [21]. Despite the increased fears of liquid mercury toxicity in the past years, a stable attention is given to the development of electroanalytical methods that utilize hanging mercury drop [22] or amalgam electrodes [23-25]. The most common electrode reaction involves twostep mechanism corresponding initially to a four-electron reduction of the $\mathrm{NO}_{2}$ group and the second signal with the reduction of the previously formed hydroxylamine group to the $\mathrm{NH}_{2}$ group involving two electrons [26]. There are also possible other reaction mechanisms depending on the type of electrode material, supporting electrolyte $\mathrm{pH}$, and so forth. Due to high hydrogen overpotential mercury-based working electrodes were found suitable for voltammetric determination of nitroaromatic molecules.

Up to date there was no voltammetric work dealing with elaboration of electroanalytical method of nitrothalisopropyl determination. Thus the goal of this work was aimed at the development of a simple and sensitive method for the aforementioned fungicide determination.

\section{Experimental}

2.1. Apparatus. All electrochemical measurements were performed with microAutolab potentiostat (EcoChemie, Netherlands) through electrochemical software version GPES 4.9. A three-electrode cell was employed incorporating a hanging mercury drop electrode (AGH University, Cracow), an $\mathrm{Ag} / \mathrm{AgCl}(3.0 \mathrm{M} \mathrm{KCl})$ reference electrode, and a $\mathrm{Pt}$ wire as a counter electrode. No special pretreatment of electrochemical station was needed prior to the measurements except degassing the working solution in the voltammetric cell with pure argon $(5 \mathrm{~N})$. Mass transport was achieved with a Teflon-coated magnetic stirrer operated by M164 stand (mtm-anko). Measurements of $\mathrm{pH}$ were made using a $\mathrm{pH}$-meter (Elmetron, Poland) with a combined glass electrode. All experiments were performed at room temperature $20 \pm 1^{\circ} \mathrm{C}$.

2.2. Solutions. All chemicals used were of analytical grade. Double distilled demineralized water was exploited throughout experiments. Nitrothal-isopropyl was purchased from Dr. Ehrenstorfer Gmbh (Augsburg, Germany) and used as received. $25 \mathrm{~mL}$ of a $1.00 \mathrm{mmol} \mathrm{L}^{-1}$ stock standard solution was prepared by dissolving $7.41 \mathrm{mg}$ of NT in a mixture of ethanol and water $(1: 1, \mathrm{v}: \mathrm{v})$. Solutions with higher dilution were freshly prepared before measurements from the stock standard solution. Britton-Robinson (BR) buffer solutions of different $\mathrm{pH}$ values were prepared by the addition of sodium hydroxide solution to a phosphoric, boric, and acetic acid mixture while citrate buffers were composed of sodium citrate in combination with required amount of hydrochloric acid. The final $\mathrm{pH}$ was controlled and adjusted using a $\mathrm{pH}$ meter.

2.3. Voltammetric Procedure. $10 \mathrm{~mL}$ of buffer solution was placed in an electrochemical cell containing a specific amount of analyzed NT standard solution. In order to remove dissolved oxygen degassing was performed before each measurement by passing through an argon stream. Electrochemical measurements of nitrothal-isopropyl were carried out with SWSV and recorded in the potential range from 0.0 to to $2.0 \mathrm{~V}$. The SW voltammetric parameters were as follows: frequency $200 \mathrm{~Hz}$, step potential $5 \mathrm{mV}$, and amplitude $50 \mathrm{mV}$ with accumulation at $0.0 \mathrm{~V}$ for $45 \mathrm{~s}$.

\section{Results and Discussion}

3.1. Electrochemical Behavior. Nitrothal-isopropyl is an electroactive compound and square wave adsorptive stripping voltammograms recorded in its presence show two welldefined reduction signals, first close to -0.1 and second approximately at $-0.6 \mathrm{~V}$ (Figure 2). For analytical purposes signal at less negative potential value was chosen due to increased sensitivity caused by higher response.

The influence of the supporting electrolyte $\mathrm{pH}$ on the electrochemical behavior of nitrothal-isopropyl was evaluated with the peak potential and current analysis. The electrochemical reduction of NT was investigated in the $\mathrm{pH}$ range $2.0-12.0$ in $0.04 \mathrm{MBR}$ buffer solution (inset in Figure 2). NT signals were observed in the whole studied $\mathrm{pH}$ range. The observed analytical peak current was highly dependent on the supporting electrolyte $\mathrm{pH}$. The maximum peak current was observed at $\mathrm{pH}$ 2.5. The peak potentials shifted significantly towards more negative values with $\mathrm{pH}$ increment. The cathodic peak potential relocation can be specified with the following equation: $E_{p}(\mathrm{~V})=0.017(\mathrm{~V})-$ $0.046 \cdot \mathrm{pH} ; r=0.998$. The slope of those dependencies is close to the theoretical value of $59.0 \mathrm{mV} \mathrm{pH}^{-1}$ and suggests protons involvement in the electroreduction of nitrothal-isopropyl most probably with equal number as electrons. The same analysis was performed in citrate buffer in the $\mathrm{pH}$ range 1.53.5 where the highest signal was again observed at $\mathrm{pH}$ 2.5. As can be seen (Figure 2(b)) observed peak current is much 


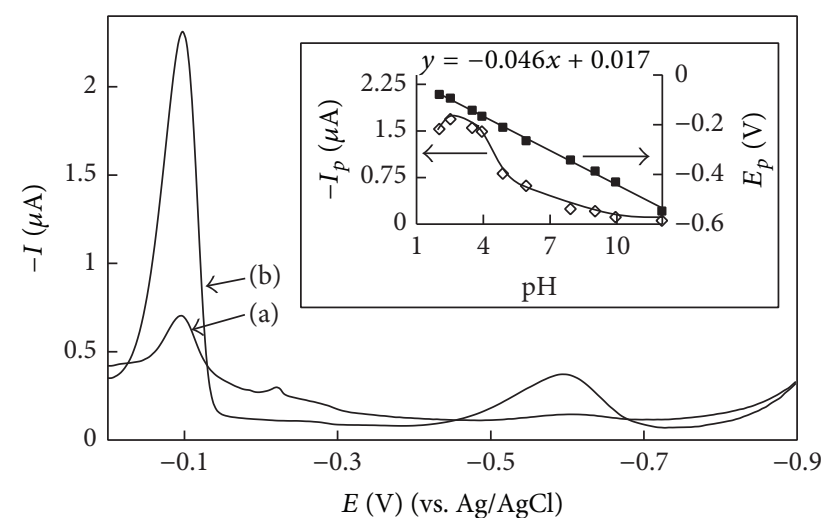

FIGURE 2: SW voltammograms for $2 \times 10^{-6} \mathrm{~mol} \mathrm{~L}^{-1} \mathrm{NT}$ solution in citrate (a) and Britton-Robinson (b) buffer $(\mathrm{pH}=2.5)$, frequency $50 \mathrm{~Hz}$, step potential $5 \mathrm{mV}$, and amplitude $50 \mathrm{mV}$. Inset presents $\mathrm{pH}$ dependence of nitrothal-isopropyl analytical peak current intensity and position in BR buffer.

higher in BR buffer and therefore this supporting electrolyte with $\mathrm{pH} 2.5$ was selected and applied in further experiments.

The optimization of square wave adsorptive stripping voltammetric parameters for nitrothal-isopropyl determination was a crucial step in preparation of electroanalytical method. The results show significant influence of square wave voltammetric parameters on the NT reduction signals (data not shown). The step potential $\left(\Delta E_{s}\right)$, the amplitude $(\Delta E)$, and the frequency $(f)$ were studied within the variable ranges of $1-7 \mathrm{mV}, 10-140 \mathrm{mV}$, and $8-500 \mathrm{~Hz}$, respectively. The peak shape and current response for NT were greatly affected by varying step potential values. Taking into account signal shape for analytical purposes, step potential equal to $5 \mathrm{mV}$ was chosen for further studies. The current response of NT increased linearly with amplitude up to $40 \mathrm{mV}$; above this value minor regression of the signal was noticed. Also ratio between peak current and half peak width suggests this value as optimal amplitude. In the range of studied square wave frequencies a nonlinear dependence between $f$ and peak current was observed. Significant signal shape deterioration was caused when frequency values higher than $250 \mathrm{~Hz}$ were applied. Keeping also in mind that the background current increases at higher frequencies an optimal value of $200 \mathrm{~Hz}$ was selected. Thus, for determination of NT the optimal values of square wave voltammetric parameters were found to be frequency $200 \mathrm{~Hz}$; amplitude $40 \mathrm{mV}$; and step potential $5 \mathrm{mV}$. Next, stripping parameters were optimized in the range $0-180 \mathrm{~s}$ and $0.25--0.05 \mathrm{~V}$ for accumulation time $\left(t_{\mathrm{acc}}\right)$ and potential $\left(E_{\text {acc }}\right)$, respectively. $E_{\text {acc }}$ of $0.0 \mathrm{~V}$ was found to be suitable since the peak current was gradually increasing with accumulation potential shift towards less positive value and a significant drop of the signal at $E_{\text {acc }}=-0.05 \mathrm{~V}$ was observed. The dependence of peak current on accumulation time shows constant increments in the peak current up to $45 \mathrm{~s}$ and further continuous decline. In both cases the peak position shifted slightly towards more negative potentials when increasing analyzed parameter. As the most optimal accumulation potential $0.0 \mathrm{~V}$ and time $45 \mathrm{~s}$ were selected.

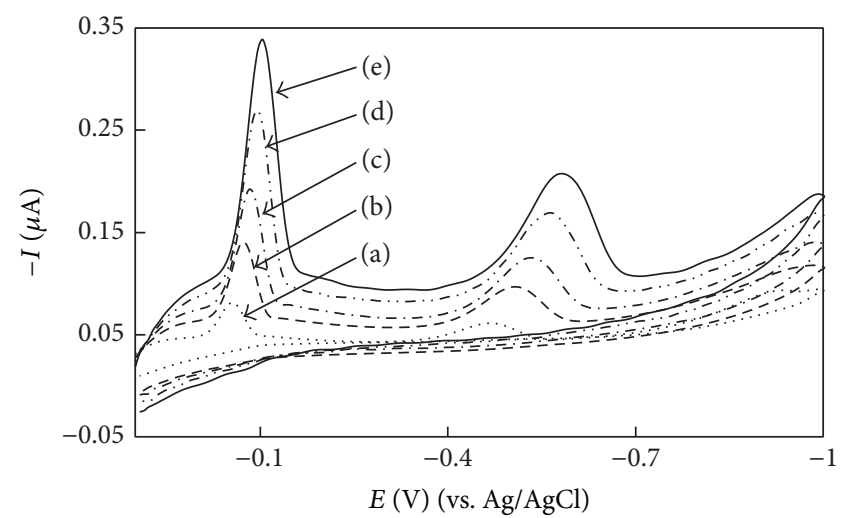

FIGURE 3: Cyclic voltammograms for $5.0 \times 10^{-6} \mathrm{~mol} \mathrm{~L}^{-1} \mathrm{NT}$ solution in Britton-Robinson buffer ( $\mathrm{pH}=2.5$ ) at the scan rates (a) 20, (b) 75, (c) 150, (d) 300 , and (e) $500 \mathrm{mV} \mathrm{s}^{-1}$.

Cyclic voltammetry was used to study the NT electrochemical behavior. The potential scan was started at $\mathrm{pH}$ 2.5 from $0.0 \mathrm{~V}$ to the negative direction and reversed at $-2.0 \mathrm{~V}$ back to the starting potential. As can be seen in Figure 3 NT manifests two separated reduction peaks, related to irreversible two-step process as there is no evidence of corresponding oxidation signal. The influence of scan rate on NT peak current was investigated from 20 to $500 \mathrm{mV} \mathrm{s}^{-1}$ as well. When the scan rate increased, cathodic peaks shifted in more negative direction as expected from an irreversible reaction. Linear dependence between peak current and square root of scan rate was observed $\left(I_{p}=-3.74 \times 10^{-7} v^{1 / 2}-1.8 \times 10^{-8}, r=\right.$ 0.999 ) indicating diffusional nature of electrode processes. It was confirmed by constructing the plot of logarithm of peak intensity $(\mu \mathrm{A})$ versus the logarithm of scan rate $(\mathrm{V} / \mathrm{s})$. The equation was $\log I_{p}(\mu \mathrm{A})=0.58 \log v\left(\mathrm{~V} \mathrm{~s}^{-1}\right)-6.43(r=$ $0.989)$. Calculated slope for this dependence was close to 0.5 which is attributed to processes controlled by diffusion $[27,28]$.

The above-described cyclic voltammograms, $\mathrm{pH}$ effect, and literature survey on the reduction of aromatic nitro compounds $[22,25,29,30]$ suggest the following electrode reaction mechanism. The reduction peak appearing at less negative potential could be attributed to the reduction of the $-\mathrm{NO}_{2}$ group through a single four-electron four-proton irreversible step into $\mathrm{NHOH}$ group. Furthermore, the next peak corresponds to further reduction of hydroxylamine group to an appropriate amino group with involvement of both two protons and two electrons.

3.2. Electroanalytical Application. The dependence between the cathodic peak current and NT concentration was examined using SWAdSV (Figure 4). A linear relationship was observed over the range from $2 \times 10^{-7}$ to $2 \times 10^{-6} \mathrm{~mol} \cdot \mathrm{L}^{-1}$ in $0.04 \mathrm{MBR}$ buffer solution ( $\mathrm{pH}$ 2.5) under the optimum conditions. The calibration curve was calculated using least square equation. Table 1 provides the characteristic of the calibration plot.

The LOD and LOQ values of the method were obtained based on $k \mathrm{SD} / b$ ( $k=3$ for LOD, $k=10$ for LOQ, resp., 
TABLE 1: Quantitative determination of nitrothal-isopropyl in BR buffer; $\mathrm{pH}=2.5$ with SWSV. Basic statistic data of the regression line.

\begin{tabular}{lc}
\hline Linear concentration range $\left(\mathrm{mol} \mathrm{L}^{-1}\right)$ & $2.00 \times 10^{-7}-2.00 \times 10^{-6}$ \\
Slope of calibration graph $\left(\mathrm{A} \mathrm{L} \mathrm{mol}^{-1}\right)$ & $4.28 \pm 0.08$ \\
Intercept $(\mu \mathrm{A})$ & $0.11 \pm 0.01$ \\
Correlation coefficient & 0.999 \\
Number of measurements & 6 \\
LOD $\left(\mathrm{mol} \mathrm{L}^{-1}\right)$ & $3.46 \times 10^{-8}$ \\
LOQ $\left(\mathrm{mol} \mathrm{L}^{-1}\right)$ & $1.15 \times 10^{-7}$ \\
\hline
\end{tabular}

TABLE 2: Recovery and precision of the NT peak currents at various nitrothal-isopropyl concentrations.

\begin{tabular}{lccc}
\hline \multicolumn{2}{c}{ Concentration } & Precision & \\
Given & $\begin{array}{c}\text { Found } \\
{\left[\mu \mathrm{mol} \mathrm{L}^{-1}\right]}\end{array}$ & CV [\%] & Recovery [\%] \\
\hline 0.200 & 0.202 & 1.4 & 101 \\
0.400 & 0.389 & 3.7 & 97.3 \\
0.600 & 0.577 & 5.5 & 96.3 \\
0.800 & 0.816 & 3.7 & 102 \\
1.00 & 1.02 & 3.4 & 103 \\
2.00 & 1.99 & 1.8 & 99.5 \\
\hline
\end{tabular}

where $\mathrm{SD}=$ standard deviation of the intercept, $b=$ slope of the calibration curve) [31]. The LOD value was well enough below the lethal dose for most of living organisms (e.g., $\mathrm{LC}_{50}$ $=0.33 \mathrm{mg} \mathrm{L}^{-1}$ in the case of trout) in natural water [32] and reflects the sufficient sensitivity of the method. The precision and recovery of the method were measured from six repeated measurements of the NT electrochemical signal at different concentrations (Table 2).

3.3. Interferences. The proposed method selectivity was investigated and evaluated with the addition of heavy metal ions, pesticides, or fungicides. The concentration of each possible interferent was increased from $1.0 \times 10^{-8}$ through $5.0 \times 10^{-8}, 1.0 \times 10^{-7}, 5.0 \times 10^{-7}$, and $1.0 \times 10^{-6}$ up to $5.0 \times$ $10^{-6} \mathrm{~mol} \mathrm{~L}^{-1}$. The recorded voltammograms were compared with the result obtained only in the presence of NT solution at a concentration of $5.0 \times 10^{-7} \mathrm{~mol} \mathrm{~L}^{-1}$. The presence of cadmium, lead, and cobalt ions did not interfere with NT voltammetric response at any of the investigated concentrations. Dodine, dinotefuran, and cyromazine also had no interference action in the studied concentration range despite presence of their signals at about $-1.1 \mathrm{~V}$. Clothianidin precluded nitrothal-isopropyl proper determination only at the highest investigated concentration although its signals were observed from the beginning at $-0.6,-0.85$, and $-1.1 \mathrm{~V}$. Strong adsorption of acibenzolar-S-methyl and metam sodium at the concentration $5.0 \times 10^{-7} \mathrm{~mol} \mathrm{~L}^{-1}$ and higher at the electrode surface caused severe drop of recorded NT voltammetric signal, although their signals present at $-0.5,-1.0$, and -0.3 , $-0.5 \mathrm{~V}$, respectively did not interfere with nitrothal-isopropyl voltammetric signal. These results suggest that in most cases

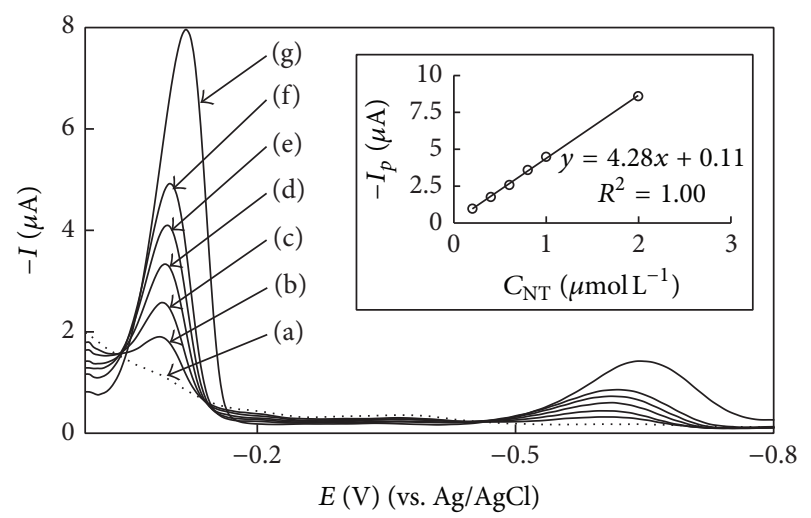

FIGURE 4: SWAdS voltammograms recorded in BR buffer $\mathrm{pH} 2.5$ with increasing nitrothal-isopropyl concentration $C_{\mathrm{NT}}=0$ (a), $2.0 \times 10^{-7}$ (b), $4.0 \times 10^{-7}$ (c), $6.0 \times 10^{-7}$ (d), $8.0 \times 10^{-7}$ (e), 1.0 $\times 10^{-6}(\mathrm{f})$, and $2.0 \times 10^{-6} \mathrm{~mol} \mathrm{~L}^{-1}(\mathrm{~g})$. The other experimental conditions were $\mathrm{SW}$ amplitude $50 \mathrm{mV}$, step potential $5 \mathrm{mV}$, frequency $200 \mathrm{~Hz}$, accumulation time $45 \mathrm{~s}$, and accumulation potential $0 \mathrm{~V}$. Inset: corresponding calibration line.

the method is selective and can be used in cases of simple environmental samples without significant deterioration.

3.4. Analysis in Spiked Water Samples. Water samples were spiked with nitrothal-isopropyl at the $4.0 \times 10^{-7} \mathrm{~mol} \cdot \mathrm{L}^{-1}$ concentration. Six replicate experiments were performed along with standard addition method to determine NT in spiked environmental samples. Exemplary voltammograms obtained during studies are presented in Figure 5. The consecutive standard additions of nitrothal-isopropyl have caused respective increments on the related peak at $-100 \mathrm{mV}$ (Figure 5). No matrix effects nor signal shifting/deteriorations were visualized. The reliability of the proposed square wave voltammetric method was investigated by assaying nitrothalisopropyl in water samples. A series of water samples were used to further investigate the accuracy of the proposed method. Analysis results are summarized in Table 3. The received results imply that the evaluated method is accurate, selective, and precise sufficiently enough to be introduced in routine analysis.

\section{Conclusion}

The above-described data clearly demonstrate the possible use of the hanging mercury drop electrode for square wave adsorptive stripping voltammetric determination of nitrothal-isopropyl. Since the proposed methodology is fast and of high precision and accuracy therefore it can be used for NT quantification in water samples with no matrix effects on the measurable response. All the data received using the optimized experimental conditions and voltammetric parameters acknowledged the practical application and viability of the proposed methodology, ensuring a new instrument for quantification of NT in water samples. The use of SWAdSV is usually more efficient than other conventional techniques. The newly developed procedure allows accurate detection of nitrothal-isopropyl and introduces a simple, fast, selective, 
TABLE 3: Results of NT determination in spiked samples with SWAdSV.

\begin{tabular}{lcccc}
\hline Sample & Concentration given $\left[\mathrm{mol} \mathrm{L}^{-1}\right]$ & Concentration found $\left[\mathrm{mol} \mathrm{L}^{-1}\right]$ & CV [\%] & Recovery [\%] \\
\hline Tap water & \multirow{2}{*}{$4.0 \times 10^{-7}$} & $(4.1 \pm 0.5) \times 10^{-7}$ & 4.8 & 102 \\
River water (Jasień) & & $(4.2 \pm 0.1) \times 10^{-7}$ & 2.2 & 104 \\
\hline
\end{tabular}

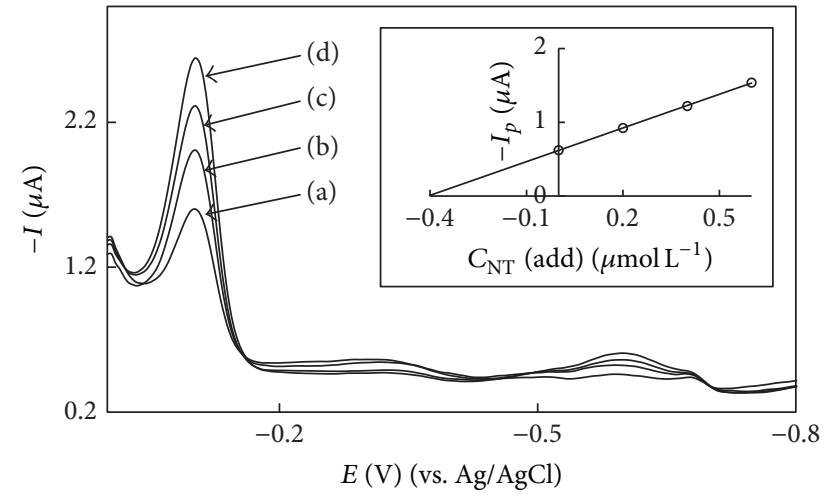

FIGURE 5: SWAdS voltammograms of nitrothal-isopropyl determination in spiked tap water samples using the standard addition method ((a) sample; (b), (c), and (d) standard additions). Experimental conditions are the same as in Figure 4. Inset: corresponding calibration curve.

and highly sensitive methodology. The capability to determine the fungicide content directly from the matrix medium or natural samples without any laborious pretreatment which are usually time-consuming and environmentally unfriendly is one of the main advantages of the method.

\section{Competing Interests}

The authors declare that they have no competing interests.

\section{Acknowledgments}

The work was financed from resources of the state funds from the Faculty of Chemistry, University of Lodz.

\section{References}

[1] K. Skrzypczyńska, K. Kuśmierek, and A. Świątkowski, "Carbon paste electrodes modified with various carbonaceous materials for the determination of 2,4-dichlorophenoxyacetic acid by differential pulse voltammetry," Journal of Electroanalytical Chemistry, vol. 766, pp. 8-15, 2016.

[2] L. C. S. Figueiredo-Filho, E. R. Sartori, and O. Fatibello-Filho, "Electroanalytical determination of the linuron herbicide using a cathodically pretreated boron-doped diamond electrode: comparison with a boron-doped diamond electrode modified with platinum nanoparticles," Analytical Methods, vol. 7, no. 2, pp. 643-649, 2015.

[3] A. Masiá, C. Blasco, and Y. Picó, "Last trends in pesticide residue determination by liquid chromatography-mass spectrometry," Trends in Environmental Analytical Chemistry, vol. 2, pp. 11-24, 2014.
[4] Deutsche Forschungsgemeinschaft, "Individual pesticide residue analytical methods (contd.)," in Manual of Pesticide Residue Analysis Volume II, chapter 3, pp. 47-112, VCH Verlag GmbH \& Co, 2006.

[5] C. C. Leandro, D. A. Bishop, R. J. Fussell, F. D. Smith, and B. J. Keely, "Semiautomated determination of pesticides in water using solid phase extraction disks and gas chromatographymass spectrometry," Journal of Agricultural and Food Chemistry, vol. 54, no. 3, pp. 645-649, 2006.

[6] R. A. Baumann, G. F. Ernst, J. T. A. Jansen et al., "Development of a multiresidue method for nitrogen-containing pesticides," Fresenius' Journal of Analytical Chemistry, vol. 339, no. 6, pp. 357-364, 1991.

[7] X.-L. Xu, L. Li, W.-K. Zhong, and Y.-J. He, "Multi-residue analysis of 205 crop pesticides using mini-solid phase extractionlarge volume injection-GC-MS," Chromatographia, vol. 70, no. 1-2, pp. 173-183, 2009.

[8] S. Butz and H.-J. Stan, "Screening of 265 pesticides in water by thin-layer chromatography with automated multiple development," Analytical Chemistry, vol. 67, no. 3, pp. 620-630, 1995.

[9] L. Švorc, "Determination of caffeine: a comprehensive review on electrochemical methods," International Journal of Electrochemical Science, vol. 8, no. 4, pp. 5755-5773, 2013.

[10] S. Smarzewska, J. Pokora, A. Leniart, N. Festinger, and W. Ciesielski, "Carbon paste electrodes modified with graphene oxides-comparative electrochemical studies of thioguanine," Electroanalysis, vol. 28, no. 7, pp. 1562-1569, 2016.

[11] V. Mirceski and R. Gulaboski, "Recent achievements in squarewave voltammetry a review," Macedonian Journal of Chemistry and Chemical Engineering, vol. 33, no. 1, pp. 1-12, 2014.

[12] E. Demir and R. İnam, "Square wave voltammetric determination of fomesafen herbicide using modified nanostructure carbon paste electrode as a sensor and application to food samples," Food Analytical Methods, 2016.

[13] R. Piech, J. Wymazała, J. Smajdor, and B. Paczosa-Bator, "Thiomersal determination on a renewable mercury film silverbased electrode using adsorptive striping voltammetry," Analytical Methods, vol. 8, no. 5, pp. 1187-1193, 2016.

[14] N. Karadas-Bakirhan, M. Gumustas, B. Uslu, and S. A. Ozkan, "Simultaneous determination of amlodipine besylate and rosuvastatin calcium in binary mixtures by voltammetric and chromatographic techniques," Ionics, vol. 22, pp. 277-288, 2016.

[15] N. Lezi and A. Economou, "Voltammetric determination of neonicotinoid pesticides at disposable screen-printed sensors featuring a sputtered bismuth electrode," Electroanalysis, vol. 27, no. 10, pp. 2313-2321, 2015.

[16] V. Mirceski, D. Guziejewski, M. Bozem, and I. Bogeski, "Characterizing electrode reactions by multisampling the current in square-wave voltammetry," Electrochimica Acta, vol. 213, pp. 520-528, 2016.

[17] V. Mirceski, S. Smarzewska, and D. Guziejewski, "Measuring the electrode kinetics of vitamin B2 at a constant time window of a square wave voltammetric experiment," Electroanalysis, vol. 28, no. 2, pp. 385-393, 2016. 
[18] V. Mirčeski, D. Guziejewski, and R. Gulaboski, "Electrode kinetics from a single square-wave voltammogram," Macedonian Journal of Chemistry and Chemical Engineering, vol. 34, no. 1, 2015.

[19] D. Guziejewski, V. Mirceski, and D. Jadresko, "Measuring the electrode kinetics of surface confined electrode reactions at a constant scan rate," Electroanalysis, vol. 27, no. 1, pp. 67-73, 2015.

[20] J. Pearson, "The reduction of nitrocompounds at the droppingmercury cathode," Transactions of the Faraday Society, vol. 44, pp. 683-697, 1948.

[21] K. Pecková, J. Barek, T. Navrátil, B. Yosypchuk, and J. Zima, "Voltammetric determination of nitronaphthalenes at a silver solid amalgam electrode," Analytical Letters, vol. 42, no. 15, pp. 2339-2363, 2009.

[22] D. Guziejewski, S. Skrzypek, A. Łuczak, and W. Ciesielski, "Cathodic stripping voltammetry of clothianidin: application to environmental studies," Collection of Czechoslovak Chemical Communications, vol. 76, no. 2, pp. 131-142, 2011.

[23] D. Deýlová, B. Yosypchuk, V. Vyskočil, and J. Barek, "Voltammetric determination of 4-nitrophenol and 5-nitrobenzimidazole using different types of silver solid amalgam electrodes-a comparative study," Electroanalysis, vol. 23, no. 7, pp. 1548-1555, 2011.

[24] D. Deýlová, V. Vyskočil, and J. Barek, "Voltammetric determination of 2-amino-6-nitrobenzothiazole at two different silver amalgam electrodes," Electrochimica Acta, vol. 62, pp. 335-340, 2012.

[25] D. Guziejewski, M. Brycht, A. Nosal-Wiercińska, S. Smarzewska, W. Ciesielski, and S. Skrzypek, "Electrochemical study of the fungicide acibenzolar-s-methyl and its voltammetric determination in environmental samples," Journal of Environmental Science and Health-Part B Pesticides, Food Contaminants, and Agricultural Wastes, vol. 49, no. 8, pp. 550-556, 2014.

[26] J. Grimshaw, Electrochemical Reactions and Mechanisms in Organic Chemistry, Elsevier, New York, NY, USA, 2000.

[27] E. Laviron, "Theoretical study of a $1 e, 1 \mathrm{H}^{+}$surface electrochemical reaction (four-member square scheme) when the protonation reactions are at equilibrium," Journal of Electroanalytical Chemistry and Interfacial Electrochemistry, vol. 109, no. 1-3, pp. 57-67, 1980.

[28] B. Uslu, B. Dogan, S. A. Özkan, and H. Y. Aboul-Enein, "Electrochemical behavior of vardenafil on glassy carbon electrode: determination in tablets and human serum," Analytica Chimica Acta, vol. 552, no. 1-2, pp. 127-134, 2005.

[29] P. Zuman, "Half a century of research using polarography," Microchemical Journal, vol. 57, no. 1, pp. 4-51, 1997.

[30] J. A. Squella, S. Bollo, and L. J. Núñez-Vergara, "Recent developments in the electrochemistry of some nitro compounds of biological significance," Current Organic Chemistry, vol. 9, no. 6, pp. 565-581, 2005.

[31] L. B. O. Dos Santos, G. Abate, and J. C. Masini, "Determination of atrazine using square wave voltammetry with the Hanging Mercury Drop Electrode (HMDE)," Talanta, vol. 62, no. 4, pp. 667-674, 2004.

[32] http://www.agropages.com/AgroData/Detail-1021.htm. 

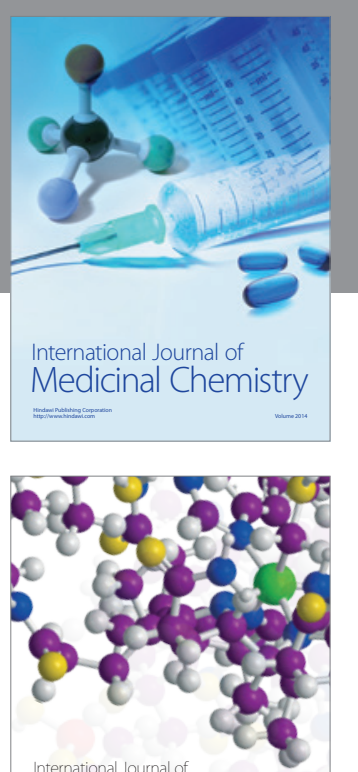

Carbohydrate Chemistry

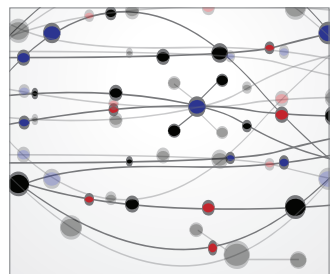

The Scientific World Journal
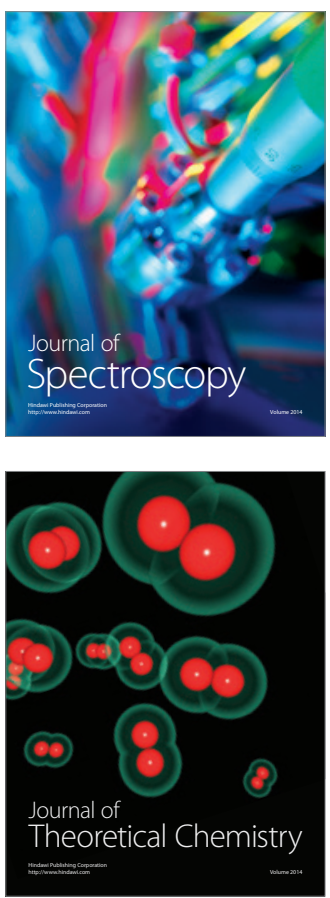
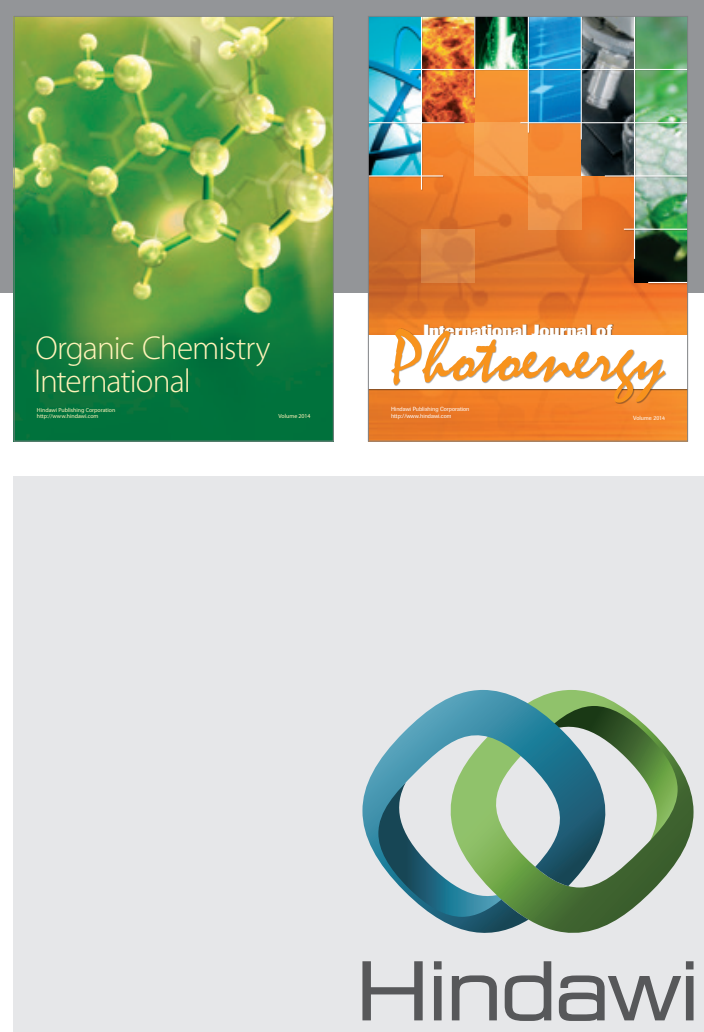

Submit your manuscripts at

http://www.hindawi.com

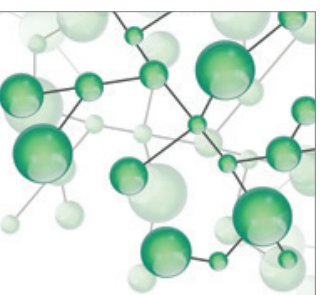

International Journal of

Inorganic Chemistry

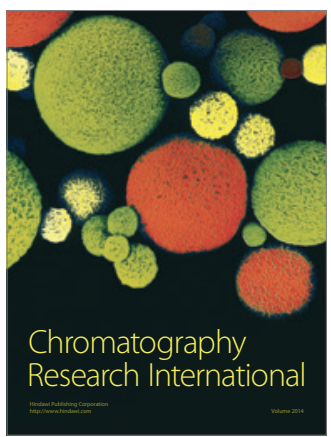

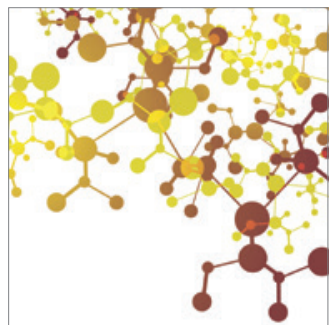

Applied Chemistry
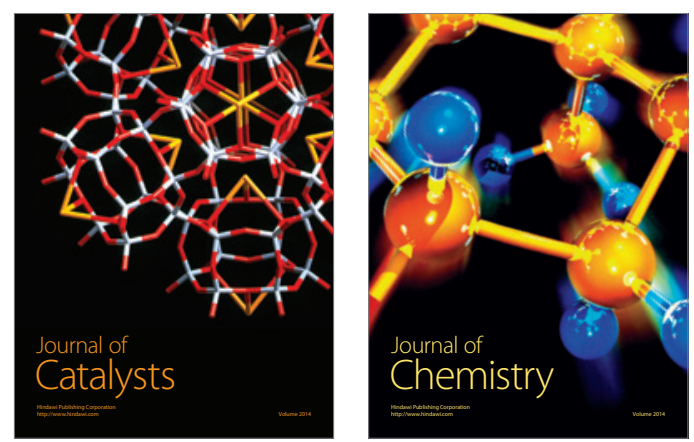
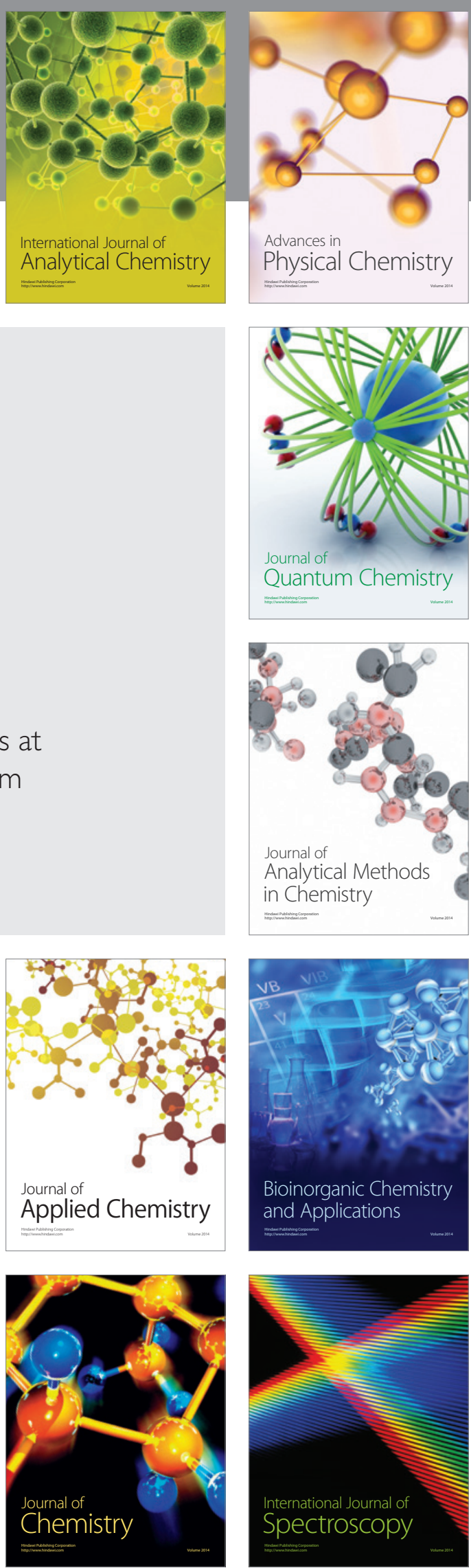